\title{
"Análisis de estrategias de integración económica en la región de América Latina y el Caribe para afrontar la pandemia de COVID-19, 2020"
}

Palomino Mendoza, Mirian del Rosario mdpalominom@ucvvirtual.edu.pe https://orcid.org/0000-0002-5972-1692 Universidad César Vallejo. Lima - Perú

Dr. Mori Paredes, Manuel Alberto Mmorip@ucv.edu.pe M2paredes@ hotmail.com https://orcid.org/0000-0002-9687-492X Universidad César Vallejo. Lima - Perú

Mg. Rocca Carvajal, Yadit Yrocca@ucv.edu.pe https://orcid.org/0000-0002-5851-830X Universidad César Vallejo. Lima - Perú

Mg. Panche Rodriguez, Odoña Beatriz Opancher@ucv.edu.pe

\section{RESUMEN} https://orcid.org/0000-0002-1629-1776 Universidad César Vallejo. Lima - Perú

El Análisis de estrategias de integración económica en la región de América Latina y el Caribe para afrontar la pandemia de COVID-19, 2020, nos indica que los países miembros de la región han tomado diversas acciones a favor de salvaguardar a su población en los diversos ámbitos que la pandemia ha afectado, principalmente a: la economía, la salud y educación.

En el trabajo de investigación se empleó la ficha de análisis documental como instrumento y como técnica la observación y análisis documental.

Muchos de los países miembros de la región han tomado acciones en favor de su nación, siendo algunas muy acertadas como creación de fondos, y apoyo de los diversos organismos internacionales; por otro lado, tenemos otras decisiones que pudieron estar mejor encaminadas.

Esta problemática nos ha llevado a tomar conciencia como países, y manejar un plan de contingencia y recursos para así prever futuras catástrofes y /o pandemias que nos agobien como nación.

Palabras Clave: Integración económica, América Latina y el Caribe, COVID-19. 
"Analysis of economic integration strategies in the Latin American and Caribbean region to face the COVID-19 pandemic, 2020"

\begin{abstract}
The Analysis of economic integration strategies in the Latin American and Caribbean region to face the COVID-19 pandemic, 2020, indicates that the member countries of the region have taken various actions in favor of safeguarding their population in the various areas that the pandemic has affected, mainly: the economy, health and education.

In the research work, the document analysis sheet was used as an instrument and documentary observation and analysis as a technique.

Many of the member countries of the region have taken actions in favor of their nation, some of which are very successful, such as the creation of funds and support from the various international organizations; on the other hand, we have other decisions that could have been better directed.

This problem has led us to become aware as countries, and to manage a contingency plan and resources in order to anticipate future catastrophes and / or pandemics that overwhelm us as a nation.
\end{abstract}

Keywords: Economic integration, Latin America and the Caribbean, COVID-19.

Artículo recibido: 05 de Mayo 2021 Aceptado para publicación: 20 de Junio 2021 Correspondencia: drcesarleonvelarde@gmail.com Conflictos de Interés: Ninguna que declarar 


\section{INTRODUCCIÓN}

Actualmente todos los países del mundo se encuentran afrontando la misma amenaza sanitaria (COVID-19), de la cual los diferentes gobiernos están tomando diversas acciones de emergencia para intentar el restablecimiento de la integración de las economías, el sistema de salud y el comercio en el mercado internacional, ya que estos son los pilares de los PBI de todas las naciones.

(OMS,2020) dice que: "COVID-19 es una enfermedad infecciosa recién descubierta causada por el coronavirus. Antes del brote en Wuhan, China en diciembre de 2019, se desconocían nuevos virus y nuevas enfermedades." Al no tener un precedente en la historia sobre esta enfermedad, los países se encuentran en aislamiento, parando de esta manera las actividades económicas y comerciales, en el ámbito local como internacional. El término integración económica se utiliza para asociar a las economías de la región, así mismo beneficiarse con la supresión de barreras en el comercio internacional, haciendo que la unificación aumente y las barreras disminuyan, logrando que las negociaciones surjan con mayor éxito comercial.

Esta crisis pandémica mundial que vivimos ahora, no tiene punto de comparación respecto a las anteriores (gripe española, asiática y de Hong Kong, H1N1, SARS, MERS y Ébola), ya que en estas últimas sí se logró controlar el nivel de contagio y sólo afectó a países de economías débiles o en todo caso muy bajas, haciendo que el comercio y la integración económica en el mercado internacional no se vea afectado de gran manera.

(Bárcenas, A, 2020) nos dice que "los países miembros de la región sufren esta pandemia desde un punto más vulnerable que el resto del mundo, ya que la CEPAL, había previsto un aumento en la economía de la región del 1,3\% sin embargo con esta crisis sanitaria, humanitaria y social se prevé una caída del 1,8\% del PBI”.

La región depende de los volúmenes de exportación, y estos valores se verán directamente afectados ya que aumentarán los costos en la cadena de valor y logística por implementación de un nuevo protocolo de seguridad y sanidad hacia el producto o servicio a exportarse.

Según las desigualdades sociales y económicas en la región el empleo se afectará desproporcionadamente en las personas pobres y de estrato social frágil, y como medida para contrarrestar la falta de empleo aumentará en mayor magnitud la informalidad y así mismo la tasa de trabajo infantil como medida de sobrevivencia. 
por otro lado, las tasas de pobreza en la región de ALC aumentarán considerablemente respecto al año anterior (2019).

Es por ese motivo que se necesita un plan de contingencia en la región para poder contrarrestar los efectos que se están desarrollando en plena y post pandemia, y así tomar las decisiones correctas e ir encontrando el camino más certero para incentivar el crecimiento de la economía, la protección social y laboral. es así como Brasil se encuentra liderando la tabla de los países que ha tomado más de Treinta y cuatro decisiones económicas a favor de su país, en segundo lugar, encontramos a los países de Chile, Uruguay, Colombia y Panamá con no más de Treinta y tres acciones; en tercer lugar, encontramos a Perú, Argentina, Venezuela, Cuba y Ecuador con un total de veintidós acciones económicas para afrontar la pandemia. Finalmente tenemos a Paraguay, Honduras, Nicaragua, Bolivia y México con once acciones en su economía.

Durante estos tiempos de pandemias, el comportamiento de la empresa irá cambiando así mismo el del consumidor, ya que deben acoplarse a las nuevas tendencias y necesidades ya que el mundo se encuentra parcialmente paralizado y todo este panorama se verá repercutido negativa y directamente en el empleo.

el daño en el aspecto laboral es muy pronunciado ya que ha tomado por sorpresas a los empleadores y empleados de todo el mundo y sin medidas que adaptar a sus políticas empresariales se han visto envueltos en esta difícil etapa pandémica.

La información emitida por la OIT, nos muestra un panorama sombrío y preocupante en la región, ya que al tener millones de personas desempleadas se muestra una falta de ingresos en las empresas y familias, haciendo que los gobiernos utilicen los recursos económicos de las naciones y aplicar incentivos para evitar el desplome económico, social y laboral en la región.

A partir de ahora en adelante el trabajo ya no será de la misma manera que antes de la pandemia, y es por eso que se insta a la población mundial a cuidar sus empleos, ya que se aplicarán nuevas medidas restrictivas y nuevos métodos de trabajo, una de ellas es la inserción del trabajo remoto, es así como actualmente se capta ingresos ya que los empleos presenciales se encuentran limitados a los servicios básicos.

(CEPAL, 2020) "La estimación más optimista después del brote de COVID-19 Ellos predicen que la tasa de desarrollo de la economía mundial disminuirá en un $1.0 \%$ o menos. A medida que se propaga la pandemia, los pronósticos de desarrollo han reducido el crecimiento esperado". Por ejemplo, Goldman, señaló que "el PIB anual de EE.UU. 
COVID-19 cayó un 3,8\%, la zona euro fue del 9\%, Japón fue del 2,1\% y la desaceleración económica de China sólo conducirá a un crecimiento del 3\%" (Goldman Sachs 2020).

Esta es una recesión mundial; además, las economías pueden incluso enfrentar una contracción a medio plazo y no recuperarse rápidamente ".

De darse esta contracción económica de la que hace mención Goldman, habría una reducción de bienes y servicio y eso ralentizará las actividades económicas y pondría en jaque las economías de la región.

"La crisis pandémica dejará golpeada a la economía directamente en la red de salud y los índices de mortalidad. Así mismo los efectos indirectos, se verán reflejados en la oferta y la demanda en la economía”. (Bárcena, A.2020)

Según la investigación de CEPAL, la región maneja dos fases de estrategias; a mediano y a largo plazo, las cuales cuentan con efectos directos e indirectos en diversas áreas de la economía, promoviendo la integración económica de Latinoamérica y el caribe para afrontar la pandemia de Covid-19 en la región.

En la fase de mediano plazo cuentan con una única opción, para que los efectos del COVID-19 se puedan mitigar y se pueda direccionar a un nuevo modelo de crecimiento a través de una mayor integración.

A largo plazo, la región tendrá que considerar su estrategia de crecimiento para comprender la gravedad de las crisis futuras. Por tanto, la CEPAL recomienda el establecimiento de un fondo regional para atender específicamente las carencias especiales de los países de ingresos medios y a través de éste fomentar la recuperación social, económica y productiva. También recalcó la importancia de obtener un financiamiento flexible de las organizaciones financieras internacionales. Los países en desarrollo deberían pactar colectivamente préstamos que se adecuen a sus pretensiones y servicios de deuda, y revisar las políticas graduales en los países de ingresos medianos. Todo este contexto nos lleva al siguiente problema de investigación: ¿Cómo las estrategias de integración económica en la región de américa latina y el caribe afrontan la pandemia de COVID-19? y los siguientes problemas específicos: ¿Cuáles son las estrategias de integración económica en la región de América Latina y el Caribe para afrontar la pandemia de COVID-19?, ¿Cuáles son los organismos que promueven estas estrategias de integración económica para afrontar la pandemia de COVID-19 en la región de américa latina y el caribe?,¿De qué manera los países miembros América Latina y el Caribe implementan las estrategias de integración económica para afrontar la pandemia 
de COVID-19? Y ¿Cuáles son los resultados esperados de las estrategias de integración económica para afrontar la pandemia de COVID-19 en cada país de la región de América Latina y el Caribe?

El presente trabajo de investigación da a conocer un análisis de las estrategias que promueve la Comisión Económica para América Latina y el Caribe, es por eso mismo que se plantea el objetivo general: “Analizar las estrategias de integración económica en la región de américa latina y el caribe para afrontar la pandemia de COVID-19”, seguido de sus objetivos específicos: "Describir las estrategias de integración económica en la región de américa latina y el caribe para afrontar el covid-19", "Describir los organismos que promueven las estrategias de integración económica para afrontar la pandemia de COVID-19 en la región de América latina y el caribe", "Describir la respuesta de los países miembros de américa latina y el caribe frente a las estrategias", "Describir los efectos de las estrategias de integración económica y las relaciones comerciales en los países de la región".

De nuestros problemas generales y específicos surge nuestra Hipótesis general: las estrategias de integración económica en la región de américa latina y el caribe permiten afrontar la pandemia de COVID-19, y nuestras hipótesis específicas Existen organismos gubernamentales que promueven las estrategias de integración económica para afrontar la pandemia de COVID-19 en la región de américa latina y el caribe, Los países miembros América Latina y el Caribe implementan las estrategias de integración económica para afrontar la pandemia de COVID-19 en la región de América Latina y el Caribe, .Las estrategias de integración económica permiten resultados esperados para afrontar la pandemia de COVID-19 en la región de América Latina y el Caribe.

\section{ESTRATEGIAS METODOLÓGICAS O MATERIALES Y MÉTODOS}

\section{Técnicas e Instrumentos de Recolección de Datos}

"Las técnicas de recopilación de datos pueden verificar las preguntas planteadas. Cada encuesta determinará la técnica que se utilizará, y cada técnica determinará las herramientas, los medios o los medios que utilizará". Bavaresco, A. (2006, p.95)

En este trabajo de investigación, se utilizó técnicas indirectas de análisis documental para recopilar información. El autor dice que la técnica de análisis documental utiliza nuestros sentidos sistemáticamente para capturar la realidad y es indirecta porque la información recopilada es el resultado de observaciones anteriores. 
La observación de la literatura es solo un proceso operativo, que incluye la obtención y organización de información de revistas, informes científicos, periódicos, etc.

La técnica de observación indirecta de la literatura se eligió al abordar diversas estrategias de integración económica en América Latina y el Caribe, indicando que en los fenómenos estudiados se utilizaron métodos no invasivos, los cuales dependen de investigaciones previas y están limitados por los planes actuales.

\section{- Instrumentos de Recolección de Datos}

Palella Santa (2006, p. 137) señaló: "Las herramientas de recolección de datos son recursos que utilizan los investigadores para procesar fenómenos y extraer información de ellos. Por lo tanto, la recolección de datos se realiza a través de archivos instrumentales de investigación".

"El análisis de contenido es la ciencia y la tecnología más prestigiosa en el campo de la observación de documentos". Serra Bravo (1999, p. 287).

Para Bernard Berelson (1999, p. 288) citado por Sierra Bravo (1999, p. 288), "La matriz de análisis de la literatura es una técnica de investigación cuyo propósito es describir de manera sistemática y cuantitativa el contenido de las publicaciones y poder Explícalo."

\section{Procedimiento}

Se Mencionan las fases del procedimiento, las cuales describen la investigación: se definió el tema del proyecto, realizando la selección de la idea, la variable de estudio, planteamiento y formulación del problema, los objetivos generales y específicos y así se redactó la introducción.

Por consiguiente, se desarrolló el marco teórico, siendo el sustento de la investigación por medio de la revisión exhaustiva de las teorías y antecedentes de la variable de estudio ya definida previamente.

Una vez conceptualizada la variable, Categorías y subcategorías se procedió a la realización de la matriz de categorización apriorística, para la realización del instrumento de recolección de datos.

Se realizó el marco metodológico que se utilizó en esta investigación, haciendo referencia al escenario de estudio, los participantes de la investigación, instrumento y técnica de recolección de datos y se diseñó la ficha de análisis documentario.

\section{Método de Análisis de Datos}

En la presente investigación, el medio usado para reunir los datos determinó el procedimiento para tratar y analizar la información fué la ficha de análisis documental, la 
cual permitió organizar y sintetizar la información más relevante y así mismo dando una respuesta al problema planteado.

\section{RESULTADOS Y DISCUSIÓN}

\section{RESULTADOS}

Estrategias económicas de américa latina y el caribe

PRUEBA DE HIPOTESIS GENERAL HO: LAS ESTRATEGIAS DE INTEGRACION NO SON SIGNIFICATIVAS. H1: LAS ESTRATEGIAS DE INTEGRACIÓN SI SON SIGNIFICATIVAS. RESULTADO: DE LA APLICACION DE LA PRUEBA T DE STUDENT SE EVIDENCIÓ QUE LAS ESTRATEGIAS DE INTEGRACIÓ SON SIGNIFICATIVAS

Tabla Nº1: Estadísticas de Muestra Única

Estadísticas de muestra única

\begin{tabular}{|l|r|r|r|r|}
\hline & $\mathrm{N}$ & Media & \multicolumn{1}{|c|}{$\begin{array}{c}\text { Desviación } \\
\text { estándar }\end{array}$} & $\begin{array}{c}\text { Media de error } \\
\text { estándar }\end{array}$ \\
\hline ESTRATEGIAS & 8 & 4,50 & 2,449 &, 866 \\
VALORES RELATIVOS & 8 & 68,25 & 17,103 & 6,047 \\
\hline
\end{tabular}

Fuente: Elaboración Propia

Tabla Nº2: Prueba de Muestra Única

Prueba de muestra única

\begin{tabular}{|c|c|c|c|c|c|c|}
\hline & \multicolumn{6}{|c|}{ Valor de prueba $=0$} \\
\hline & \multirow[b]{2}{*}{$\mathrm{t}$} & \multirow[b]{2}{*}{ gl } & \multirow[b]{2}{*}{ Sig. (bilateral) } & \multirow{2}{*}{$\begin{array}{l}\text { Diferencia de } \\
\text { medias }\end{array}$} & \multicolumn{2}{|c|}{$\begin{array}{l}\text { 95\% de intervalo de confianza de la } \\
\text { diferencia }\end{array}$} \\
\hline & & & & & Inferior & Superior \\
\hline ESTRATEGIAS & 5,196 & 7 & 001 & 4,500 & 2,45 & 6,55 \\
\hline VALORES RELATIVOS & 11,287 & 7 &, 000 & 68,250 & 53,95 & 82,55 \\
\hline
\end{tabular}

Fuente: Elaboración Propia

Se empleó la revisión documental para analizar el primer objetivo, se utilizó como herramientas tecnológicas la plataforma de la Comisión Económica para América Latina y el Caribe (CEPAL).

Según el observatorio de CEPAL, los países miembros de la región han tomado un total de 924 acciones en lo que va transcurriendo la pandemia de COVID-19.

Dentro de las principales acciones y/o estrategias tomadas según las principales áreas tenemos:

- En política fiscal se han tomado 206 acciones, representadas por el $96 \%$ de las acciones del total tomadas por los países de la región. 
- En Política monetaria se han tomado 106 acciones, representadas por el 69\% de las acciones del total tomadas por los países de la región.

- En Política empresarial se han tomado 252 acciones, representadas por el $87 \%$ de las acciones del total tomadas por los países de la región.

- En Restricción de la actividad económica (incluidas tiendas y centros comerciales) se han tomado 64 acciones, representadas por el $84 \%$ de las acciones del total tomadas por los países de la región.

- En Controles de precios y cantidades se han tomado 38 acciones, representadas por el $51 \%$ de las acciones del total tomadas por los países de la región.

- En Estímulo Económico (incluye el valor agregado de las medidas fiscales y por separado de las garantías de crédito) se han tomado 79 acciones, representadas por el $60 \%$ de las acciones del total tomadas por los países de la región.

- En Regulación del mercado de higiene personal y productos de limpieza se han tomado 25 acciones, representadas por el $45 \%$ de las acciones del total tomadas por los países de la región.

- En Alivio de la deuda y suspensión de pagos de crédito (individuos, microempresarios) se han tomado 53 acciones, representadas por el $66 \%$ de las acciones del total tomadas por los países de la región.

- En Otros se han tomado 87 acciones, representadas por el $72 \%$ de las acciones del total tomadas por los países de la región. 
Análisis de estrategias

Gráfico Nº1: Estrategias de Integración Económica Vs Acciones Tomadas

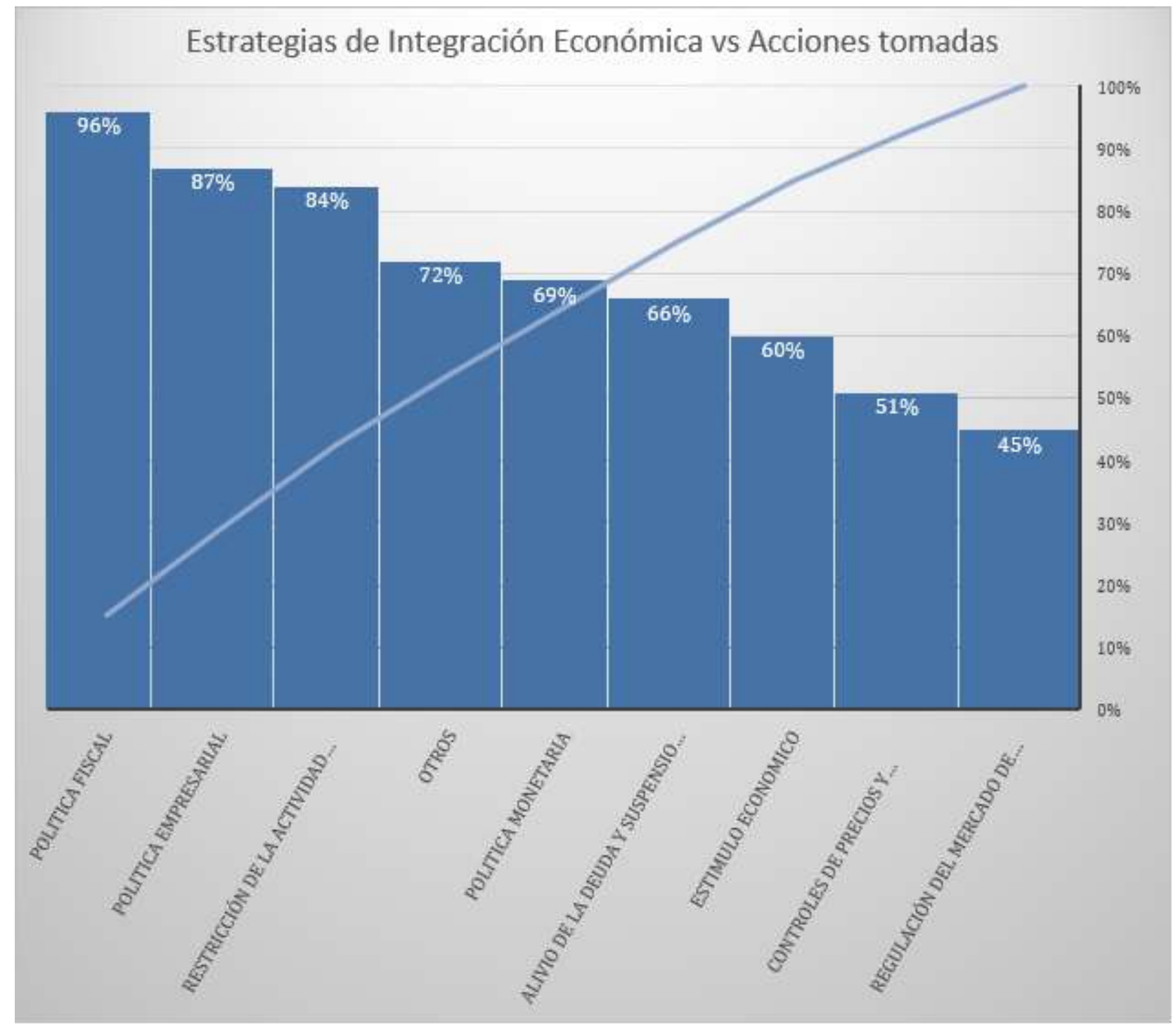

Fuente: Observatorio COVID-19 - CEPAL 
Gráfico $\mathbf{N}^{\circ}$ 02: Porcentaje de acciones por tomadas según las estrategias

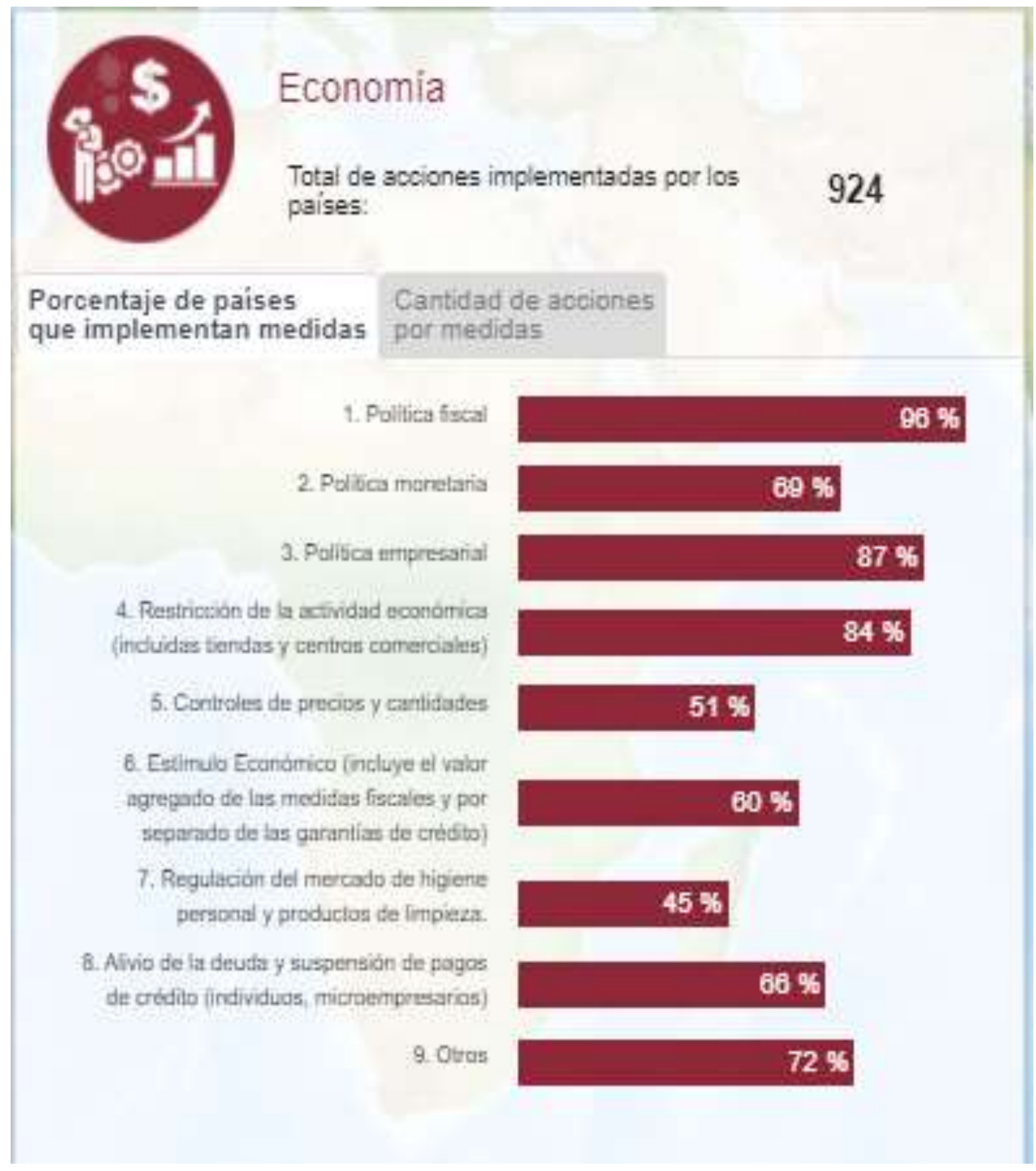

Fuente: Observatorio COVID-19-CEPAL

Dentro de la categoría $\mathrm{N}^{\circ} 01$ : Unión Aduanera, la cual considera dos (02) subcategorías, las cuales son:

- Los estados miembros de la región de América latina y el caribe con Unión Aduanera

Ciencia Latina Revista Científica Multidisciplinar, Ciudad de México, México. ISSN 2707-2207 / ISSN 2707-2215 (en línea), mayo-junio, 2021, Volumen 5, Número 3. https://doi.org/10.37811/cl_rcm.v5i3.561 p.3745 
Dentro de esta subcategoría, se encontraron los países miembros de la asociación Latinoamericana de Libre Comercio/ Asociación Latinoamericana de Integración (ALALC, ALADI), Pacto Andino/ Comunidad Andina (PA/CAN), Mercado Común del Sur (MERCOSUR), Alianza Bolivariana para los pueblos de Nuestra América - Tratado de Comercio de los Pueblos (ALBA - TCP) y Alianza del Pacifico (AP). Véase Tabla $\mathrm{N}^{\circ} 00$

La unión aduanera entre Guatemala y Honduras entró en vigencia en junio de 2017, y el proceso de profunda integración entre los dos países se estableció sobre la base legal de los instrumentos legales de integración económica centroamericana.

Tabla $\mathbf{N}^{\circ} 03$ : Uniones Aduaneras.

\begin{tabular}{|c|c|c|}
\hline Union Aduanera & Países Miembros & Fecha de Creación \\
\hline $\begin{array}{l}\text { Asociación Latinoamericana } \\
\text { de Libre Comercio/ } \\
\text { Asociación Latinoamericana } \\
\text { de r Integración } \\
\text { (ALALC/ALADI) }\end{array}$ & $\begin{array}{l}\text { Argentina, Bolivia, Brasil, } \\
\text { Chile, Colombia, Cuba, } \\
\text { Ecuador, México, Paraguay, } \\
\text { Panamá, Perú, Uruguay y } \\
\text { Venezuela }\end{array}$ & 1960 \\
\hline $\begin{array}{l}\text { Pacto Andino/ Comunidad } \\
\text { Andina (CAN) }\end{array}$ & $\begin{array}{l}\text { Bolivia, Colombia, Ecuador y } \\
\text { Perú }\end{array}$ & 1969 \\
\hline $\begin{array}{l}\text { Mercado Común del Sur } \\
\text { (MERCOSUR) }\end{array}$ & $\begin{array}{l}\text { Brasil, Argentina, Uruguay y } \\
\text { Paraguay }\end{array}$ & 1991 \\
\hline $\begin{array}{l}\text { Alianza Bolivariana para los } \\
\text { pueblos de nuestra América- } \\
\text { Tratado de Comercio de los } \\
\text { pueblos (ALBA-TCP) }\end{array}$ & $\begin{array}{l}\text { Venezuela, Ecuador y } \\
\text { Bolivia, Antigua y Barbuda, } \\
\text { Cuba, Dominica, Granada, } \\
\text { Nicaragua, San Cristobal y } \\
\text { Nieves, Santa Lucia, San } \\
\text { Vicente y Las Granadinlas y } \\
\text { Surinam }\end{array}$ & 2004 \\
\hline Alianza del Pacífico (AP) & $\begin{array}{l}\text { Chile, Colombia, Perú y } \\
\text { México }\end{array}$ & 2011 \\
\hline
\end{tabular}

Fuente: Revista Journal "Globalización, Competitividad y Gobernalidad" 
- La Balanza Comercial de los países miembros de la región de América latina y el caribe.

\section{BALANZA COMERCIAL}

(Millanes de uș)

\begin{tabular}{|c|c|c|c|c|c|}
\hline & \multicolumn{2}{|c|}{2019} & \multirow{2}{*}{$\begin{array}{c}2020 \\
\text { Ene. } \\
\text { (b) }\end{array}$} & \multicolumn{2}{|c|}{ Enoro } \\
\hline & $\begin{array}{l}\text { Ene. } \\
\text { (a) }\end{array}$ & Dic. & & $\begin{array}{c}\text { Var. \%mos } \\
\text { anterior }\end{array}$ & $\begin{array}{c}\text { Var. } \% 12 \\
\text { meses }\end{array}$ \\
\hline 1. EXPORTACIONES & 3959 & 4608 & 3895 & $-15,5$ & $-1,6$ \\
\hline Productos tradicionales & 2704 & 3236 & 2655 & $-17,9$ & $-1,8$ \\
\hline Productos no tradicionales & 1241 & 1367 & 1226 & $-10,3$ & $-1,2$ \\
\hline Otros & 13 & 5 & 13 & 147,1 & 0,8 \\
\hline 2. IMPORTACIONES & 3480 & 3388 & 3611 & 6,6 & 3,8 \\
\hline Bienes de consumo & 783 & 806 & 805 & $-0,2$ & 2,7 \\
\hline hsumos & 1693 & 1513 & 1734 & 14,6 & 2,4 \\
\hline Bienes de capital & 986 & 1058 & 1060 & 0,2 & 7,5 \\
\hline Otros bienes & 18 & 11 & 13 & 25,8 & $-27,2$ \\
\hline 3. BALANZA COMERCIAL & 479 & 1220 & 283 & & \\
\hline
\end{tabular}

Tabla N'04: Balanza Comercial

Fuente: Sunat y Bcrp

En el caso de Perú, se presentó una comparación de la balanza comercial de enero del 2019 y 2020, la cual nos indicó que el \% de variación respecto al mes anterior, es de 15.5 y la variación \% anual es del -1.6 para exportaciones.

En el caso de importaciones, el \% de variación respecto al mes anterior es de 6.6, mientras que el \% variación anual es de 3.8 .

Gráfico $\mathrm{N}^{\circ}$ : 03 - Volumen de las Exportaciones de bienes y servicios por bloque

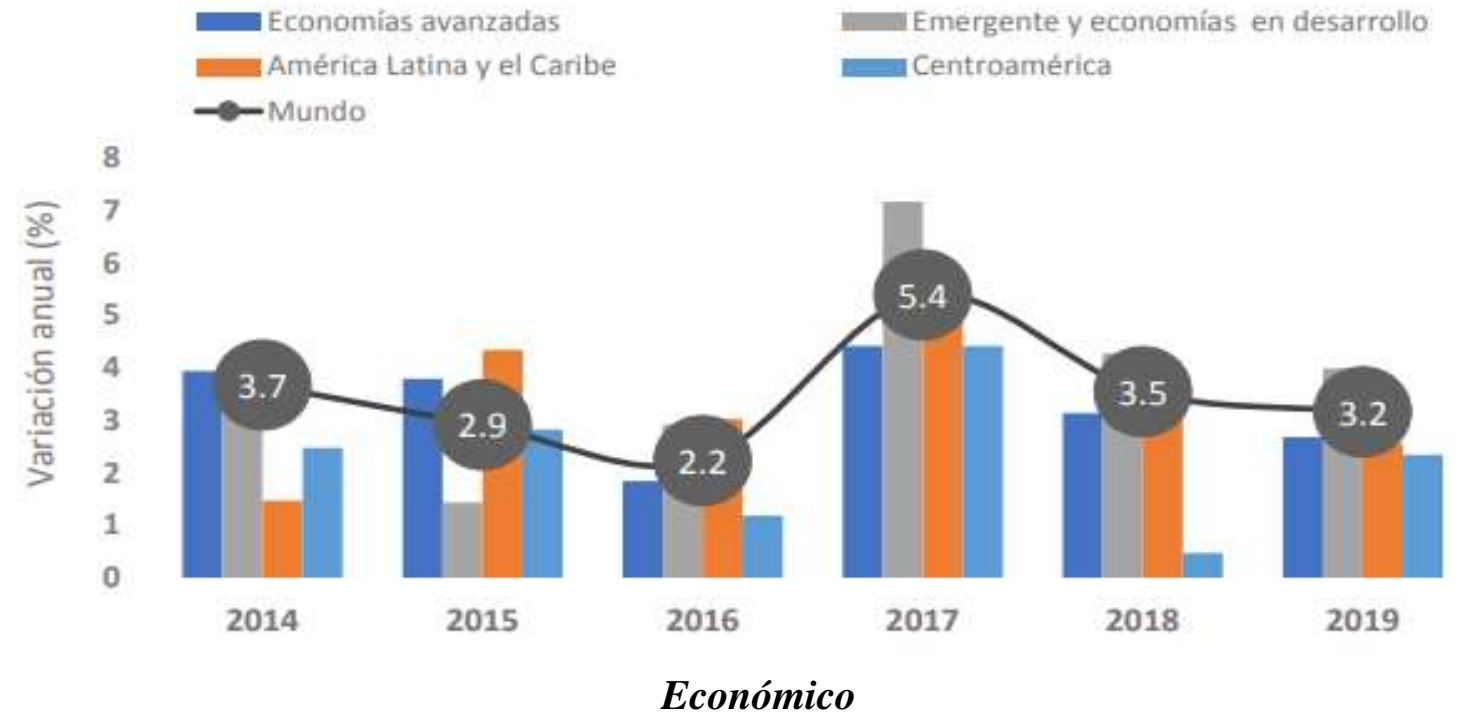

Fuente: Centro de estudios para la Integración Económica (SIECA) con datos del FMI. 
Respecto a las exportaciones en la región de américa latina desde el año 2014 hasta el 2019 se demostró cómo ha ido descendiendo el \% de Variación anual respecto a los demás bloques económicos.

\section{Gráfico $\mathrm{N}^{\circ}$ 04: Volumen de las importaciones de Bienes y servicios por bloque} económico.

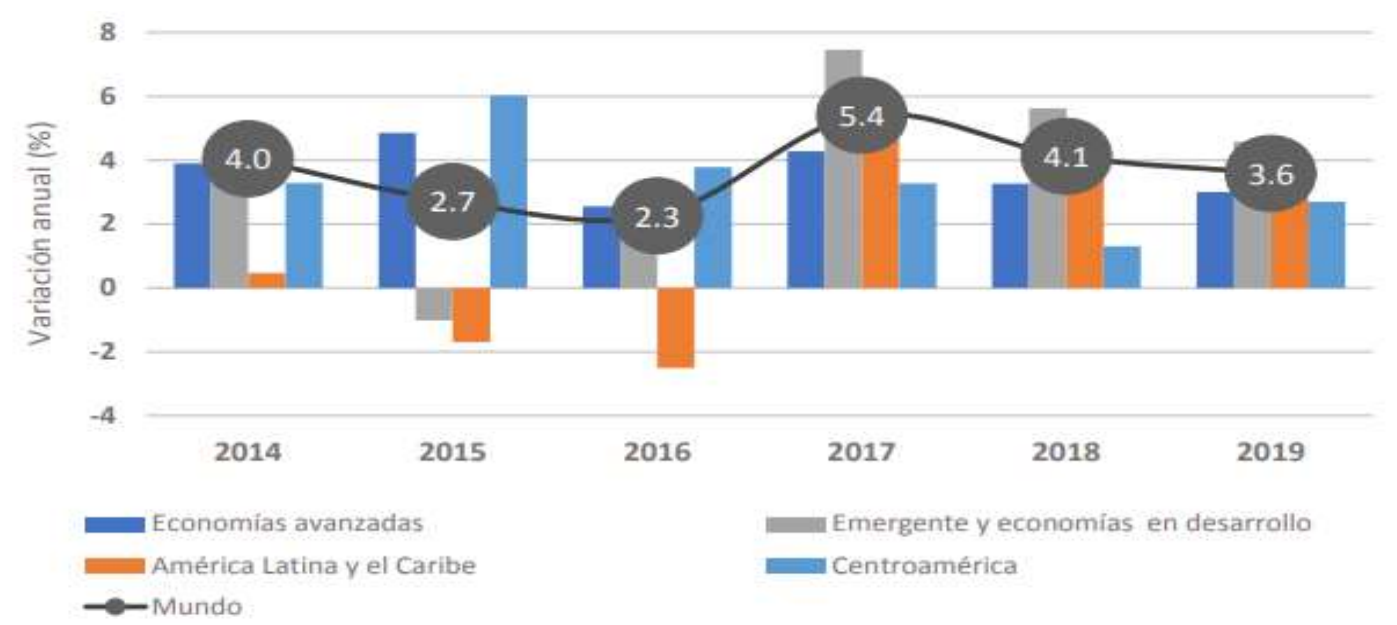

Fuente: Centro de Estudios para la Integración Económica (SIECA) con datos del FMI.

En el gráfico $\mathrm{N}^{\circ} 04$, se demostró que el porcentaje de variación de las importaciones fluctúa entre el $4 \%$ y $3.6 \%$ de variación respecto a los demás bloques económicos.

\section{Organismos no gubernamentales que promueven las estrategias de integración económica.}

En los organismos no gubernamentales tenemos a:

- El objetivo básico de la Comisión Económica para América Latina y el Caribe (CEPAL) es la promoción del desarrollo y actualización de los datos estadísticos nacionales y su comparabilidad internacional, promoviendo la cooperación internacional, regional y bilateral y la cooperación regional entre las oficinas en los países y los organismos internacionales, y cuando los recursos lo permitan. Dadas las circunstancias, preparar un plan bienal de actividades de cooperación regional e internacional para responder a las necesidades de los países de la región.

- El Banco Interamericano de Desarrollo (BID) tiene como objetivo reducir la pobreza, combatir la desigualdad social y la promoción del desarrollo económico sostenible en la región.

- Fondo Monetario Internacional (FMI), cuyo objetivo es mejorar el nivel de vida de los países miembros. 
Encontramos la categoría $\mathrm{N}^{\circ}: 02$, la cual es: Zona de libre comercio y como subcategoría: Zona de libre comercio en los países miembros de la región de américa latina y el caribe.

Los países de la región centroamericana se han comprometido a alcanzar de manera voluntaria, gradual y progresiva la Unión Económica Centroamericana. Para ello, se encuentran perfeccionando la Zona de Libre Comercio, por medio de la cual se eliminan las barreras arancelarias y no arancelarias al comercio de las mercancías originarias de la región.

La Comunidad del Caribe (CARICOM), antes Comunidad del Caribe y Mercado Común, fue establecida bajo el Tratado de Chaguaramas, que entró en vigencia el 1 de agosto de 1973. Los primeros cuatro países firmantes son Barbados, Jamaica, Guyana y Trinidad. Y Tobago. CARICOM reemplazó a la Asociación de Libre Comercio del Caribe (CARIFTA) de 1965 a 1972. La asociación se estableció para mantener una relación continua entre los países del caribe de habla inglesa después de la separación de la Unión de las Indias Occidentales el 3 de enero de 1958.

\section{Análisis de respuesta de los países miembros}

Los países de ALC reafirmaron su compromiso con el desarrollo sostenible y se destacaron en respuestas claras a todos los niveles para frenar y contrarrestar el profundo impacto de la pandemia del coronavirus (COVID-19) en la región, que no hace distinciones de límite, ideología o nivel de desarrollo.

El ministro Marmiéka advirtió en su discurso sobre la agenda 2030 que está claro que el cumplimiento de la Agenda está en riesgo. También expresó que solo se han logrado o están cerca de alcanzarse unas pocas metas, mientras que lograr las metas restantes requerirá una mayor intervención de políticas y cambios en el modelo de desarrollo actual.

Actualmente, la situación se ha complicado por el impacto de la pandemia COVID-19, de muchos sectores que obliga a los países a tomar acciones urgentes para evitar retrasos o retrocesos en la consecución de los Objetivos de Desarrollo Sostenible (ODS) y su realización. Objetivos y fortalecer las tendencias positivas en la implementación.

También se enfoca en la creación de una plataforma web acerca de los Objetivos de Desarrollo Sostenible (Portal SGD) en América Latina y el Caribe, la plataforma de conocimiento "Agenda 2030" desarrollada conjuntamente por el sistema de Naciones Unidas en la región, y el Observatorio COVID-19 En América Latina y el Caribe, esta es 
la fuente de información y análisis sobre las consecuencias económicas y sociales de la pandemia. Se puede utilizar para monitorear la evolución de la crisis y las medidas de corto, mediano y largo plazo implementadas en 33 países de Estados Unidos en América Latina y el Caribe.

Encontramos la categoría $\mathbf{N}^{\circ} 03$ : La cual es: Mercado Común y como sub categoría: Estados de América latina $y$ el caribe miembros del bloque comercial (MERCOSUR).

Los estados miembros del MERCOSUR son:

- Argentina, Brasil, Paraguay, Uruguay, Venezuela, Bolivia, Chile Colombia, Ecuador, Guyana, Perú y Surinam.

\section{Gráfico N: 05 - Objetivos del MERCOSUR}

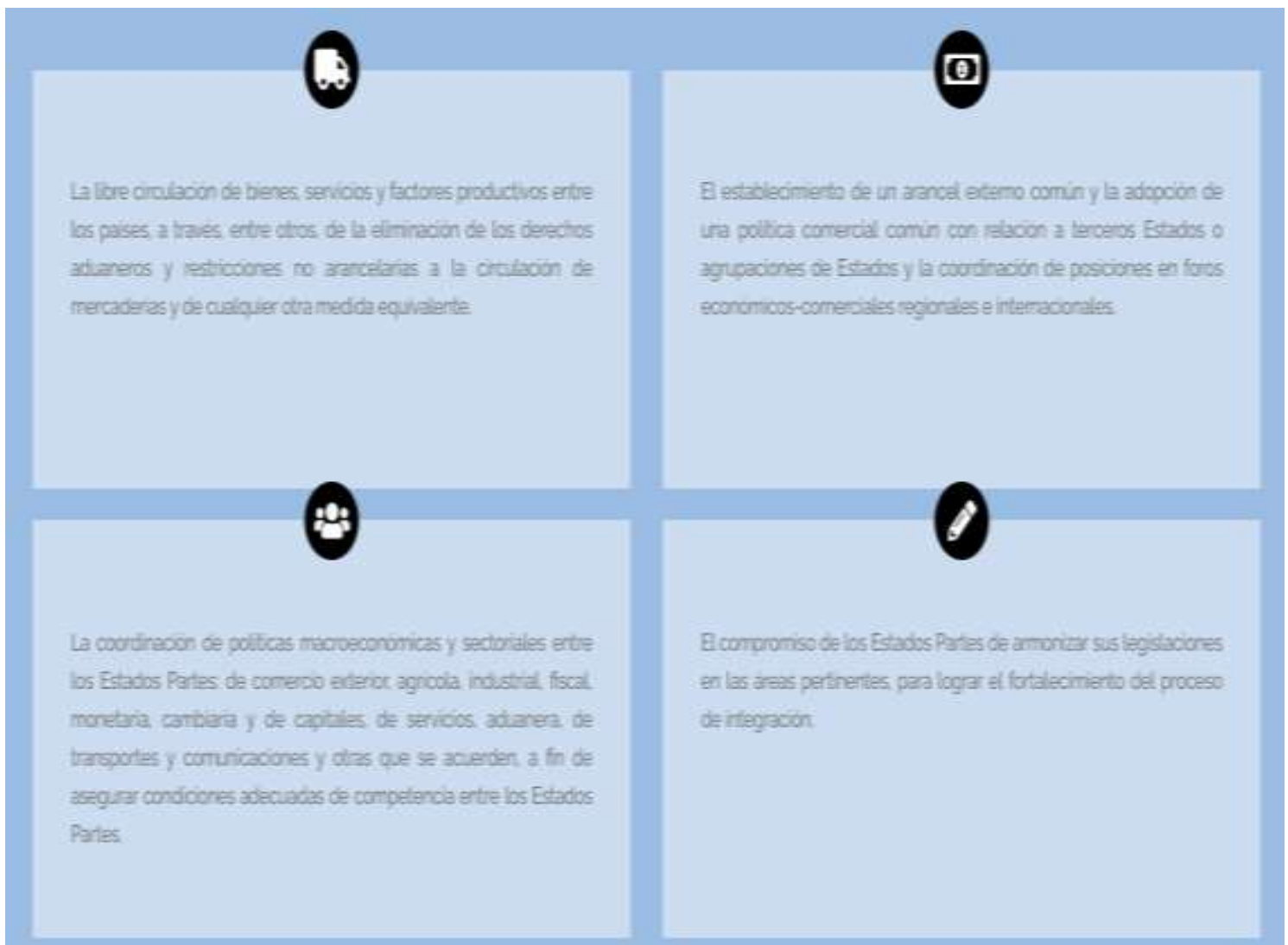

\section{Fuente: MERCOSUR}

\section{Resultados esperados de las estrategias de integración económica}

Según Adhanom, T. (2020) director de la OMS, en su boletín nos menciona que Cada país debe continuar implementando un plan de acción nacional basado en un enfoque social holístico y realizar una evaluación realista de la viabilidad de ralentizar la velocidad de transmisión y reducir la tasa de mortalidad, y luego evaluar la viabilidad de continuar realizando actividades sociales y económicas manteniendo Nivel de transmisión más 
bajo. El plan debe ser lo suficientemente flexible para responder a la situación epidemiológica en rápida evolución en diferentes partes del país, teniendo en cuenta las condiciones locales y la capacidad de respuesta. Los pilares básicos de las medidas nacionales de respuesta eficaces se detallan en el "Plan estratégico de preparación y respuesta".

Cada estrategia nacional juega un papel importante y así poder conseguir el cumplimiento de los objetivos globales y al menos debería sentar las bases para:

a) coordinar las medidas de respuesta nacionales y subnacionales.

b) Participar y movilizar a las comunidades afectadas y en riesgo.

c) Implementar las medidas de salud pública adecuadas a la situación para detener la propagación y controlar los casos esporádicos.

d) Preparar el sistema de salud para reducir la tasa de mortalidad asociada con COVID19 , mantener los servicios de salud necesarios y proteger a los trabajadores de la salud.

e) Plan de emergencia para asegurar la continuidad de las funciones y servicios públicos básicos.

\section{DISCUSIÓN}

Luego de haber descrito los resultados de la investigación respecto al Análisis de estrategias de integración económica en la región de América Latina y el Caribe para afrontar la pandemia de COVID-19, el presente capítulo comprende la discusión de los hallazgos, que siguió el mismo orden planteado en las hipótesis propuestas.

\section{Contrastación de la Hipótesis General}

Las estrategias de integración económica en la región de américa latina y el caribe permiten afrontar la pandemia de COVID-19.

Según Bonaglia, En su artículo: "Una mirada al futuro post-COVID-19: hacia un nuevo pacto social en América Latina y el Caribe". se afirma que las estrategias de integración económica que se han adoptado durante la pandemia de COVID-19, han dado resultados óptimos en esta lucha contra la pandemia que nos ha afectado, es así que las estrategias y medidas adoptadas por los países de la región han permitido que no atravesemos una segunda ola de contagios, así se confirma al término de esta investigación.

Las estrategias económicas priorizaron la salud ante la actividad económica, ya que se considera fundamental el factor humano ante la actividad económica, ya que se están 
aplicando medidas de reactivación para impulsar y levantar la economía de las diversas naciones que conforman la región.

Así mismo se realizó la prueba de $\mathrm{T}$ de student, para la hipótesis general y como resultado la significancia, es decir que nuestra hipótesis es aplicada.

\section{Contrastación de las Hipótesis Específicas}

Existen organismos no gubernamentales que promueven las estrategias de integración económica para afrontar la pandemia de COVID-19 en la región de américa latina y el caribe.

López-Calva, L. (2020). En su revista de investigación: "La ONU ayuda a América Latina para frenar urgentemente la propagación del COVID-19", publicado por el departamento de comunicación global en New York, Estados Unidos. esta investigación aplicada no experimental, no presenta técnica, instrumento y muestra debido a los datos ex post facto de dicha investigación. Afirma que la región está recibiendo ayuda de las organizaciones no gubernamentales para contrarrestar la pandemia de COVID-19, entre estos organismos tenemos a: la Organización de Naciones Unidas (ONU), Comisión Económica para América Latina y el Caribe, Banco Interamericano de Desarrollo y Banco Mundial.

Los países miembros América Latina y el Caribe implementan las estrategias de integración económica para afrontar la pandemia de COVID-19 en la región de América Latina y el Caribe,

Bonet-Morón. (2020). En su artículo de estudio económico regional del banco de la república de Colombia: "Impacto económico regional del Covid-19 en Colombia: un análisis insumo-producto".

Nos afirma que los países de la región han implementado estrategias de integración económica para contrarrestar los efectos de la pandemia de COVID-19 en las economías de los países miembros de la región de América Latina y el Caribe.

Las estrategias de integración económica permiten resultados esperados para afrontar la pandemia de COVID-19 en la región de América Latina y el Caribe.

López-Calva, L. (2020). En su artículo: “CCómo podría afectar el nuevo coronavirus a la economía de América Latina?", publicado por el departamento de comunicación global en New York, Estados Unidos. esta investigación aplicada no experimental, no presenta técnica, instrumento y muestra debido a los datos ex post facto de dicha investigación. Este estudio nos revela que gracias a la toma de acciones de las estrategias 
de integración económica se podrán mitigar los efectos de la pandemia de COVID-19 en ciertas áreas donde aún no se ha dado la reactivación económica, Ya que se ha dado por fases de apertura.

\section{CONCLUSIÓN O CONSIDERACIONES FINALES}

1) Se concluye que las estrategias de integración económica en la región de América latina y el caribe ayudan a afrontar la pandemia de COVID-19, ya que todos los países han tomado acciones sobre las estrategias propuestas.

2) La existencia de organismos no gubernamentales es favorable para los países miembros de la región de América Latina y el Caribe, ya que promueven las estrategias de integración y a su vez brindan apoyo económico para implementar nuevas medidas.

3) Los resultados esperados de la toma de acciones de las estrategias de integración económica ante una pandemia sin precedente han dejado buenas propuestas, así como otras que pueden ser mejor encaminadas.

4) Los miembros de la región, han empleado estrategias de política fiscal, política monetaria, empresarial y demás para contrarrestar los efectos del COVID-19, en sus naciones.

\section{RECOMENDACIONES}

1) La comisión económica para América Latina y el Caribe (CEPAL), la Organización de Naciones Unidas (ONU), el Banco Interamericano de Desarrollo (BID) y el Fondo Monetario Internacional (FMI), impulsan las estrategias de integración económica para los países miembros de la región de América Latina y el Caribe, y es así que los países miembros al aplicar estas estrategias en las economías de sus naciones, obtienen como resultado en su mayoría acciones favorables y otras por encaminarse de mejor manera o replantearse.

2) La pandemia de COVID-19 en los países de Latinoamérica ha sufrido directamente en su economía, ya que China es su principal socio comercial, sin embrago, las exportaciones no han parado, ya que se han visto en la necesidad de buscar nuevos mercados alternativos y así evitar la caída total de su balanza comercial.

3) Según el observatorio COVID-19 de CEPAL, se ha podido observar que la toma de acciones de estrategias de integración económica en la región ha tenido una gran diferenciación de aplicación según los países miembros de la región, como es el caso de Brasil y Colombia que han tomado 80 acciones estratégicas durante el periodo de 
Pandemia de COVID-19 a diferencia de Antigua y barbuda que solo tomo 5 acciones para su nación.

4) Se exhorta a los países miembros de la región en continuar aplicando estrategias en los planes de contingencia ante el COVID-19 para frenar los estragos económicos que está dejando la pandemia.

\section{LISTA DE REFERENCIAS}

Gomes, G., \& Tavares, M. D. C. (1998). La CEPAL y la integración económica de América Latina. Revista de la CEPAL. Recuperado de: https://bit.ly/3njqZG8

Stolovich, L. (1995). El impacto de la integración económica regional sobre el mundo del trabajo: El caso de Mercosur. Revista de Administración Pública, 87-108. Recuperado de: https://bit.ly/3nifNJX

Briceño Ruiz, J. (2013). Ejes y modelos en la etapa actual de la integración económica regional en América Latina. Estudios Internacionales (Santiago), 45(175), 9-39. Recuperado de: https://bit.ly/3oUcF7H

Barquero, A. V. (2009). Desarrollo local, una estrategia para tiempos de crisis. Apuntes del CENES, 28(47), 117-132. Recuperado de: https://bit.ly/3nf957r

Rosales, O. (2014). Integración regional: hacia una estrategia de cadenas de valor inclusivas. Revista de la CEPAL. Recuperado de: https://bit.ly/37g2DaO

Bonet-Morón, J. A., Ricciulli-Marín, D., Pérez-Valbuena, G. J., Galvis-Aponte, L. A., Haddad, E. A., Araújo-Junior, I. F., ... \& Galvis-Aponte, L. A. (2020). Impacto económico regional del Covid-19 en Colombia: un análisis insumoproducto. Documento de Trabajo sobre Economía Regional y Urbana; No. 288. Recuperado de: https://bit.ly/3qVBD8c

Bonaglia, F., Parra, S. N., \& Zamora, J. J. V. (2020). Una mirada al futuro post-COVID19: hacia un nuevo pacto social en América Latina y el Caribe. Análisis Carolina, (21), 1. Recuperado de: https://bit.ly/3nf9837

Zuta, H. R. Libre comercio y apertura comercial en la Alianza del Pacífico e impacto económico: Periodo 1970-2015. Pensamiento Crítico, 23(2), 47-72. Recuperado de: https://bit.ly/2WcxLli

López-Calva, L. (2020). Noticias ONU. ¿Cómo podría afectar el nuevo coronavirus a la economía de América Latina? Nueva York, EU. Recuperado de: https://bit.ly/348QRNk 
López-Calva, L. (2020). Noticias ONU. La ONU ayuda a América Latina para frenar urgentemente la propagación del COVID-19. Nueva York, EU. Recuperado de: https://bit.ly/3gKAcop

Werner, A. (2020). Política económica en América Latina y el Caribe en tiempo de la COVID-19 [Mensaje en un blog]. Diálogo a fondo, el blog del FMI sobre temas económicos de américa latina. Recuperado de: https://bit.ly/3qSO3xP

Alami, Z. (2019). ¿Qué es el comercio intrarregional y por qué está afectando a la globalización?. Barcelona, España. Recuperado de: https://bit.ly/37ZkzFU

Briceño Ruiz, José. (2013). Ejes y modelos en la etapa actual de la integración económica regional en América Latina. Estudios internacionales (Santiago), 45(175), 9-39. https://bit.ly/3aku59x

CEPAL (1999). "La conformación del área de libre comercio de las américas" (octubre, 1999). Recuperado de: https://bit.ly/3a6N7Qo

Petit Primera, José Gregorio (2014). LA TEORÍA ECONÓMICA DE LA INTEGRACIÓN Y SUS PRINCIPIOS FUNDAMENTALES. Revista Venezolana de Análisis de Coyuntura, XX (1), 137-162. [Fecha de consulta 23 de julio de 2020]. ISSN: 1315-3617. Disponible en: https://bit.ly/2LtRU45

Cepal (2020). The Pandemic's Impacts on the Hardest-Hit Production Sectors Will Affect One Third of Employment in the Region and One Fourth of GDP. Santiago de Chile, Chile. Recuperado de: https://bit.ly/38fsM9d

Cepal (2020). ECLAC Calls for Moving Towards a Big Push for Sustainability as a Strategy for Emerging from the Current Crisis. Santiago de Chile, Chile. Recuperado de: https://bit.ly/2Lp60DM

Cepal (2020). Alicia Bárcena Calls for Moving towards a New Development Paradigm that Closes the Social Gap with a Rights-based Approach and that Respects the Planet's Limits. Santiago de Chile, Chile. Recuperado de: https://bit.ly/37cpeVQ

Cepal (2020). Building Back Better after COVID-19 Necessitates Doing So with Equality and Sustainability: ECLAC. Santiago de Chile, Chile. Recuperado de: https://bit.ly/3oOo0WJ

Cepal (2020). ECLAC Presents to the Community of Latin American and Caribbean States a Study on the Economic Impact of COVID-19 that Includes an Observatory on Measures and Instruments along with Recommendations and 
Proposals for Confronting the Disease. Santiago de Chile, Chile. Recuperado de: https://bit.ly/3m93D4Q

Cepal (2020). Greater International Financial Cooperation is Crucial for Latin American and Caribbean Countries to be Able to Face the "Perfect Storm" Unleashed by the COVID-19 Crisis. Santiago de Chile, Chile. Recuperado de: https://bit.ly/3qQn3yR

Cepal (2020). ECLAC and ILO Analyze Labour Challenges in Latin America and the Caribbean in the Wake of the COVID-19 Pandemic .Santiago de Chile, Chile. Recuperado de: https://bit.ly/346TVJS

Cepal (2020). COVID-19 Pandemic Will Lead to the Biggest Contraction in Economic Activity in the Region's History: A -5.3\% Drop in 2020. Santiago de Chile, Chile. Recuperado de: https://bit.ly/3mhCsEZ

Briceño Ruiz, José (2006). Regionalismo estratégico e interregionalismo en las relaciones externas del MERCOSUR. RECUPERADO DE: https://bit.ly/37XUuqB

Bogado L.(2019). Integración Regional en América Latina y el Caribe. Principales procesos. RECUPERADO DE: https://bit.ly/38ftaEH

Sistema de la Integración Centro Americana - SICA (S.F). Unión Aduanera. RECUPERADO DE: https://bit.ly/3a92ZSj

Balassa, B. 1974. Trade creation and trade diversion in the European Common Market: an appraisal of the evidence. The Manchester School, 42(2), pp. 93-135.

Diao, X., y Somwaru, A. 2000. An inquiry on general equilibrium effects of Mercosur an intertemporal world model. Journal of Policy Modeling, 22(5), pp. 557-588.

Frankel, J. A., Stein, E., Wei, S. 1997. Regional trading blocs in the world economic system. Washington: Peterson Institute.

Abreu, M. y Bevilaque, A.S. (1996), “Coordinación macroeconómica e integración económica”, en Krugman, P., Winters, A., et al. (ed.), Las Américas: Integración Económica en Perspectiva, Departamento Nacional de Planificación del Banco Interamericano de Desarrollo, Bogotá, pp. 269-304.

Herrero, S. 2016. El proceso de regionalización latinoamericano ¿aceptar que la cooperación es la única manera?. Regional and Sectorial Economic Studies, 16(1), pp. 171-186. 
López-Bermúdez, B., Freire-Seoane, M. J., y Pais-Montes, C. 2016. South American West Coast Economies: A Panel Data Approach. Recuperado de https://bit.ly/383STzw

Martínez-Zarzoso, I., Felicitas, N. D., y Horsewood, N. 2009. Are regional trading agreements beneficial?: Static and dynamic panel gravity models. North American Journal of Economics and Finance, 20(1), pp. 46-58. Recuperado de https://bit.ly/3a7vArt

Morineau, A. 1984. Note sur la Caractérisation Statistique d'une Classe et les Valeurstests. Bulletin Technique du Centre de Statistique et d'Informatique Appliquées, 2(1-2), pp. 20-27.

Reyes, G. E. 2008. Vulnerabilidad macroeconómica en Latinoamérica y el Caribe. Compendium Revista de Investigación Científica, 20, pp. 57-72

Stiglitz, J. E. 2002. Information and the Change in the Paradigm in Economics. The American Economic Review, 92(3), pp. 460-501.

Tinbergen, J. 1962. Shaping the World Economy: Suggestions for an International Economic Policy. New York: Twentieth Century Fund.

Rosenthal, G. (1999), “Los procesos de integración regional y las políticas sociales”, en CEPAL. (ed.), Las dimensiones sociales de la integración regional en América Latina, CEPAL, Santiago de Chile, pp. 121-132.

Wonnacott, P., y Wonnacott, J. 1981. Is Unilateral Tariff Reduction Preferable to a Custom Union? The Case of the Missing Foreing Tariffs. The American Economic Review, 71(4), pp. 704-714.

Robson, P. 1998. The economics of international integration. London: Psychology Press. 
ANEXOS

ANEXO Nº1: MATRIZ DE CATEGORIZACIÓN APRIORÍSTICA

\begin{tabular}{|c|c|c|c|c|c|c|}
\hline $\begin{array}{c}\text { Objeto de } \\
\text { estudio }\end{array}$ & $\begin{array}{c}\text { Pregunta } \\
\text { general de } \\
\text { investigación }\end{array}$ & \multicolumn{2}{|c|}{$\begin{array}{c}\text { Objetivo } \\
\text { general de } \\
\text { investigacón }\end{array}$} & $\begin{array}{c}\text { Hipotesis } \\
\text { general de } \\
\text { investigación }\end{array}$ & \multicolumn{2}{|c|}{ Preguntas de investigación } \\
\hline $\begin{array}{l}\text { AMÉRICA } \\
\text { LATINA Y } \\
\text { EL } \\
\text { CARIBE }\end{array}$ & $\begin{array}{l}\text { ¿Cómo las } \\
\text { estrategias de } \\
\text { integración } \\
\text { económica en } \\
\text { la región de } \\
\text { américa latina } \\
\text { y el caribe } \\
\text { afrontan la } \\
\text { pandemia de } \\
\text { COVID-19? }\end{array}$ & \multicolumn{2}{|c|}{$\begin{array}{l}\text { Analizar las } \\
\text { estrategias de } \\
\text { integración } \\
\text { económica en } \\
\text { la región de } \\
\text { américa latina } \\
\text { y el caribe } \\
\text { para afrontar } \\
\text { la pandemia de } \\
\text { COVID-19 }\end{array}$} & $\begin{array}{l}\text { Las estrategias } \\
\text { de integración } \\
\text { económica en } \\
\text { la región de } \\
\text { américa latina } \\
\text { y el caribe } \\
\text { permiten } \\
\text { afrontar la } \\
\text { pandemia de } \\
\text { COVID-19 }\end{array}$ & \multicolumn{2}{|c|}{$\begin{array}{l}\text { 1. ¿Cuáles son las estrategias de } \\
\text { integración económica en la región de } \\
\text { América Latina y el Caribe para } \\
\text { afrontar la pandemia de COVID-19? } \\
\text { 2. ¿Cuáles son los organismos que } \\
\text { promueven estas estrategias de } \\
\text { integración económica para afrontar la } \\
\text { pandemia de COVID-19? } \\
\text { 3. ¿De qué manera los países } \\
\text { miembros de américa latina y el } \\
\text { caribe responden a las estrategias de } \\
\text { integración económica para afrontar la } \\
\text { pandemia de COVID-19? } \\
\text { 4. ¿Cuáles son los resultados } \\
\text { esperados de las estrategias de } \\
\text { integración económica para afrontar la } \\
\text { pandemia de COVID-19 en cada país } \\
\text { de la región de américa Latina y el } \\
\text { Caribe? }\end{array}$} \\
\hline \multicolumn{3}{|c|}{ Objetivos especificos } & \multicolumn{2}{|c|}{ Hipotesis especificas } & Categorias & \\
\hline \multicolumn{3}{|c|}{$\begin{array}{l}\text { 1. Describir las estrategias de } \\
\text { integración económica en la } \\
\text { región de américa latina yel caribe } \\
\text { para afrontar la pandemia de } \\
\text { COVID-19. } \\
\text { 2. Describir los organismos } \\
\text { gubernamentales que promueven } \\
\text { las estrategias de integración } \\
\text { económica para afrontar la } \\
\text { pandemia de COVID-19. } \\
\text { 3. Analizar la respuesta de los } \\
\text { países miembros de américa latina } \\
\text { y el caribe frente a las estrategias } \\
\text { de integración económica para } \\
\text { afrontar } \\
\text { 4. Describir los resultados } \\
\text { esperados de las estrategias de } \\
\text { integración económica para } \\
\text { afrontar la pandemia de COVID- } \\
\text { 19 durante los seis primeros meses } \\
\text { en los países de la región de } \\
\text { américa Latina y el Caribe. }\end{array}$} & \multicolumn{2}{|c|}{$\begin{array}{l}\text { 1. Existen organismos no } \\
\text { gubernamentales que } \\
\text { promueven las estrategias de } \\
\text { integración económica para } \\
\text { afrontar la pandemia de } \\
\text { COVID-19 en la región de } \\
\text { américa latina y el caribe. } \\
\text { 2. Los países miembros } \\
\text { América Latina y el Caribe } \\
\text { implementan las estrategias de } \\
\text { integración económica para } \\
\text { afrontar la pandemia de } \\
\text { COVID-19 en la región de } \\
\text { América Latina y el Caribe, } \\
\text { 3. .Las estrategias de } \\
\text { integración económica } \\
\text { permiten resultados esperados } \\
\text { para afrontar la pandemia de } \\
\text { COVID-19 en la región de } \\
\text { América Latina y el Caribe. }\end{array}$} & $\begin{array}{l}\text { 1. Unión } \\
\text { Aduanera }\end{array}$ & $\begin{array}{l}\text {-Estados miembros } \\
\text { de la región de } \\
\text { América latina y el } \\
\text { caribe con Unión } \\
\text { Aduanera } \\
\text {-Balanza Comercial } \\
\text { de los países } \\
\text { miembros de la } \\
\text { región de América } \\
\text { latina y el caribe } \\
\text { Zona de libre } \\
\text { comercio en los } \\
\text { países miembros de } \\
\text { la región de américa } \\
\text { latina y el caribe. } \\
\text { dos de América latina } \\
\text { y el caribe miembros } \\
\text { del bloque comercial } \\
\text { (MERCOSUR }\end{array}$ \\
\hline
\end{tabular}


ANEXO 02. INSTRUMENTO: FICHA DE INVESTIGACIÓN

\begin{tabular}{|l|l|}
\hline FICHA DE ANÁLISIS DOCUMENTAL & $\begin{array}{l}\text { La CEPAL y la integración económica de América } \\
\text { Latina. }\end{array}$ \\
\hline Nombre del Documento & Gomes, G., \& Tavares, M. D. C. \\
\hline Autor & $\begin{array}{l}\text { Gomes, G., \& Tavares, M. D. C. (1998). La } \\
\text { CEPAL y la integración económica de América } \\
\text { Latina. Revista de la CEPAL. Recuperado de: } \\
\text { https://repositorio.cepal.org/handle/11362/12138 }\end{array}$ \\
\hline Palabras claves de búsqueda & CEPAL, Integración económica. \\
\hline Palabras claves del texto & Integración Económica \\
\hline Ubicación (dirección electrónica específica) & https://repositorio.cepal.org/handle/11362/12138 \\
\hline $\begin{array}{l}\text { Descripción del aporte del tema } \\
\text { seleccionado }\end{array}$ & $\begin{array}{l}\text { Información a cerca de los aspectos centrales que } \\
\text { conforman la esencia del diagnóstico del desarrollo } \\
\text { en los países de América Latina. }\end{array}$ \\
\hline Enfoque & Cuantitativo \\
\hline Alcance y diseño & $\begin{array}{l}\text { Alcance: Descriptivo - Exploratorio } \\
\text { Diseño: No Experimental. }\end{array}$ \\
\hline
\end{tabular}

Fuente: Elaboración propia.

ANEXO 03. INSTRUMENTO: FICHA DE INVESTIGACIÓN

\begin{tabular}{|c|c|}
\hline \multicolumn{2}{|l|}{ FICHA DE ANÁLISIS DOCUMENTAL } \\
\hline Nombre del Documento & $\begin{array}{l}\text { La ONU ayuda a América Latina para frenar urgentemente } \\
\text { la propagación del COVID-19 }\end{array}$ \\
\hline Autor & López-Calva, L. \\
\hline $\begin{array}{l}\text { Referencia } \text { Bibliográfica } \\
\text { norma APA }\end{array}$ & $\begin{array}{l}\text { López-Calva, L. (2020). Noticias ONU. La ONU ayuda a } \\
\text { América Latina para frenar urgentemente la propagación del } \\
\text { COVID-19. Nueva York, EU. Recuperado de: } \\
\text { https://www.un.org/es/coronavirus/articles/onu-apoya- } \\
\text { america-latina-contra-propagacion-covid-19 }\end{array}$ \\
\hline Palabras claves de $b$ & ONU, América Latina, COVID-19 \\
\hline Palabras claves del & Causas del impacto económico, América L \\
\hline $\begin{array}{l}\text { Ubicación (dirección electrónica } \\
\text { específica) }\end{array}$ & $\begin{array}{l}\text { https://www.un.org/es/coronavirus/articles/onu-apoya- } \\
\text { america-latina-contra-propagacion-covid-19 }\end{array}$ \\
\hline $\begin{array}{l}\text { Descripción del aporte del tema } \\
\text { seleccionado }\end{array}$ & $\begin{array}{l}\text { Identificación de las causas } \\
\text { a la propagación de COVID }\end{array}$ \\
\hline Enfoque & Cuantitativo, Cualitativo \\
\hline Alcance y diseño & $\begin{array}{l}\text { Alcance: Descriptivo - Exploratorio } \\
\text { Diseño: No Experimental. }\end{array}$ \\
\hline
\end{tabular}

Fuente: Elaboración propia.

\section{ANEXO Nº4: INSTRUMENTO: FICHA DE INVESTIGACIÓN}

\section{FICHA DE ANÁLISIS DOCUMENTAL}

\begin{tabular}{|l|l|}
\hline \multicolumn{2}{|l|}{ FICHA DE ANÁLISIS DOCUMENTAL } \\
\hline Nombre del Documento & $\begin{array}{l}\text { Building Back Better after COVID-19 Necessitates Doing } \\
\text { So with Equality and Sustainability }\end{array}$ \\
\hline Autor & CEPAL \\
\hline $\begin{array}{l}\text { Referencia Bibliográfica según } \\
\text { norma APA }\end{array}$ & $\begin{array}{l}\text { Cepal (2020). Building Back Better after COVID-19 } \\
\text { Necessitates Doing So with Equality and Sustainability: } \\
\text { ECLAC. Santiago de Chile, Chile. Recuperado de: } \\
\text { https://www.cepal.org/en/pressreleases/building-back- }\end{array}$ \\
\hline
\end{tabular}




\begin{tabular}{|l|l|}
\hline & $\begin{array}{l}\text { better-after-covid-19-necessitates-doing-so-equality-and- } \\
\text { sustainability }\end{array}$ \\
\hline Palabras claves de búsqueda & PBI \\
\hline Palabras claves del texto & PBI, COVID-19 \\
\hline $\begin{array}{l}\text { Ubicación (dirección electrónica } \\
\text { específica) }\end{array}$ & $\begin{array}{l}\text { https://www.cepal.org/en/pressreleases/building-back- } \\
\text { better-after-covid-19-necessitates-doing-so-equality-and- } \\
\text { sustainability }\end{array}$ \\
\hline $\begin{array}{l}\text { Descripción del aporte del tema } \\
\text { seleccionado }\end{array}$ & $\begin{array}{l}\text { Se señaló que el PIB anual de EE.UU. COVID-19 cayó un } \\
3,8 \%, \text { la zona euro fue del 9\%, Japón fue del 2,1\% y la } \\
\text { desaceleración económica de China sólo conducirá a un } \\
\text { crecimiento del 3\%. }\end{array}$ \\
\hline Enfoque & \begin{tabular}{l} 
Cuantitativo, Cualitativo \\
\hline Alcance y diseño
\end{tabular} \\
$\begin{array}{l}\text { Alcance: Descriptivo - Exploratorio } \\
\text { Diseño: No Experimental. }\end{array}$ \\
\hline
\end{tabular}

Fuente: Elaboración propia.

\section{ANEXO N05: INSTRUMENTO: FICHA DE INVESTIGACIÓN}

\section{FICHA DE ANÁLISIS DOCUMENTAL}

\begin{tabular}{|l|l|}
\hline FICHA DE ANÁLISIS DOCUMENTAL \\
\hline Nombre del Documento & $\begin{array}{l}\text { LA TEORÍA ECONÓMICA DE LA INTEGRACIÓN Y } \\
\text { SUS PRINCIPIOS FUNDAMENTALES. }\end{array}$ \\
\hline Autor & Petit Primera, José Gregorio \\
\hline $\begin{array}{l}\text { Referencia Bibliográfica según } \\
\text { norma APA }\end{array}$ & $\begin{array}{l}\text { Petit Primera, José Gregorio (2014). LA TEORÍA } \\
\text { ECONÓMICA DE LA INTEGRACIÓN Y SUS } \\
\text { PRINCIPIOS FUNDAMENTALES. Revista Venezolana } \\
\text { de Análisis de Coyuntura, XX (1), 137-162. [Fecha de } \\
\text { consulta 23 de julio de 2020]. ISSN: 1315-3617. Disponible } \\
\text { en: } \\
\text { https://www.redalyc.org/articulo.oa?id=364/364333515007 }\end{array}$ \\
\hline Palabras claves de búsqueda & Teoría de Integración Económica \\
\hline Palabras claves del texto & Bella Ballassa, teorías de integración económica \\
\hline $\begin{array}{l}\text { Ubicación (dirección electrónica } \\
\text { específica) }\end{array}$ & $\underline{\text { https://www.redalyc.org/articulo.oa?id=364/364333515007 }}$ \\
\hline $\begin{array}{l}\text { Descripción del aporte del tema } \\
\text { seleccionado }\end{array}$ & $\begin{array}{l}\text { La integración de los países de la región de américa latina y } \\
\text { el caribe se basa en su cercanía geográfica, idioma, e } \\
\text { historia de liberación de esclavitud y conquista. }\end{array}$ \\
\hline Enfoque & Cuantitativo, Cualitativo \\
\hline Alcance y diseño & $\begin{array}{l}\text { Alcance: Descriptivo - Exploratorio } \\
\text { Diseño: No Experimental. }\end{array}$ \\
\hline
\end{tabular}

Fuente: Elaboración propia.

\section{ANEXO Nº6: INSTRUMENTO: FICHA DE INVESTIGACIÓN}

\begin{tabular}{|l|l|}
\hline FICHA DE ANÁLISIS DOCUMENTAL \\
\hline Nombre del Documento & $\begin{array}{l}\text { "La conformación del área de libre comercio de las } \\
\text { américas" }\end{array}$ \\
\hline Autor & CEPAL \\
\hline $\begin{array}{l}\text { Referencia Bibliográfica según } \\
\text { norma APA }\end{array}$ & $\begin{array}{l}\text { CEPAL (1999). "La conformación del área de libre } \\
\text { comercio de las américas". Recuperado de: } \\
\text { https://repositorio.cepal.org/bitstream/handle/11362/2729/ } \\
\text { 1/LCmexL405_es.pdf }\end{array}$ \\
\hline Palabras claves de búsqueda & Área de libre comercio \\
\hline Palabras claves del texto & $\begin{array}{l}\text { Zona de libre comercio, bella Ballassa, teorías de } \\
\text { integración económica, fases }\end{array}$ \\
\hline
\end{tabular}




\begin{tabular}{|l|l|}
\hline $\begin{array}{l}\text { Ubicación (dirección electrónica } \\
\text { específica) }\end{array}$ & $\begin{array}{l}\text { https://repositorio.cepal.org/bitstream/handle/11362/2729/ } \\
\text { 1/LCmexL405 es.pdf }\end{array}$ \\
\hline $\begin{array}{l}\text { Descripción del aporte del tema } \\
\text { seleccionado }\end{array}$ & $\begin{array}{l}\text { Bella Ballassa, según su teoría, nos dice que el proceso de } \\
\text { integración económica inicia con la zona de libre comercio. }\end{array}$ \\
\hline Enfoque & Cuantitativo, Cualitativo \\
\hline Alcance y diseño & $\begin{array}{l}\text { Alcance: Descriptivo - Exploratorio } \\
\text { Diseño: No Experimental. }\end{array}$ \\
\hline
\end{tabular}

Fuente: Elaboración propia.

ANEXO N07: INSTRUMENTO: FICHA DE INVESTIGACIÓN

\begin{tabular}{|c|c|}
\hline \multicolumn{2}{|c|}{ FICHA DE ANÁLISIS DOCUMENTAL } \\
\hline Nombre del Documento & $\begin{array}{l}\text { Política económica en América Latina y el Caribe en tiempo } \\
\text { de la COVID-19 }\end{array}$ \\
\hline Autor & Wermer A. \\
\hline $\begin{array}{l}\text { Referencia Bibliográfica según } \\
\text { norma APA }\end{array}$ & $\begin{array}{l}\text { Werner, A. (2020). Política económica en América Latina y } \\
\text { el Caribe en tiempo de la COVID-19 [Mensaje en un blog]. } \\
\text { Diálogo a fondo, el blog del FMI sobre temas económicos } \\
\text { de américa latina. Recuperado de: https://blog- } \\
\text { dialogoafondo.imf.org/?p=13241 }\end{array}$ \\
\hline Palabras claves de búsqueda & Economía y crisi pandemica \\
\hline Palabras claves del texto & Crisis $\mathrm{p}$ \\
\hline $\begin{array}{l}\text { Ubicación (dirección electrónica } \\
\text { específica) }\end{array}$ & https://blog-dialogoafondo.imf.org/?p=13241 \\
\hline $\begin{array}{l}\text { Descripción del aporte del tema } \\
\text { seleccionado }\end{array}$ & $\begin{array}{l}\text { "La crisis pandémica dejará golpeada a la economía } \\
\text { directamente en los sistemas de salud y las tasas de } \\
\text { mortalidad. Así mismo los efectos indirectos, se verán } \\
\text { reflejados en la oferta y la demanda en la economía" }\end{array}$ \\
\hline Enfoque & Cuantitativo, Cualitativo \\
\hline Alcance y diseño & $\begin{array}{l}\text { Alcance: Descriptivo - Explorat } \\
\text { Diseño: No Experimental. }\end{array}$ \\
\hline
\end{tabular}

Fuente: Elaboración propia.

\section{ANEXO N08: INSTRUMENTO: FICHA DE INVESTIGACIÓN}

\begin{tabular}{|c|c|}
\hline \multicolumn{2}{|l|}{ FICHA DE ANÁLISIS DOCUMENTAL } \\
\hline Nombre del Documento & Desarrollo local, una estrategia para tiempos de crisis. \\
\hline Autor & Barquero, A. \\
\hline $\begin{array}{l}\text { Referencia Bibliográfica } \\
\text { norma APA }\end{array}$ & $\begin{array}{l}\text { Barquero, A. V. (2009). Desarrollo local, una estrategia } \\
\text { para tiempos de crisis. Apuntes del CENES, 28(47), 117- } \\
132 . \quad \text { Recuperado } \\
\text { https://www.redalyc.org/pdf/4795/479549575007.pdf }\end{array}$ \\
\hline Palabras claves de búsqueda & Cadenas de valor \\
\hline Palabras claves del texto & $\begin{array}{l}\text { Exportaciones en américa latina y el caribe, cadenas de } \\
\text { valor }\end{array}$ \\
\hline $\begin{array}{l}\text { Ubicación } \text { (dirección electrónica } \\
\text { específica) }\end{array}$ & https://www.redalyc.org/pdf/4795/479549575007.pdf \\
\hline $\begin{array}{l}\text { Descripción del aporte del tema } \\
\text { seleccionado }\end{array}$ & $\begin{array}{l}\text { la destrucción de las cadenas de valor mundiales y } \\
\text { regionales provocarán una fuerte disminución de las } \\
\text { exportaciones de América Latina y el Caribe. }\end{array}$ \\
\hline Enfoque & Cuantitativo, Cualitativo \\
\hline Alcance y diseño & $\begin{array}{l}\text { Alcance: Descriptivo - Exploratorio } \\
\text { Diseño: No Experimental. }\end{array}$ \\
\hline
\end{tabular}

Fuente: Elaboración propia.

Ciencia Latina Revista Científica Multidisciplinar, Ciudad de México, México.

ISSN 2707-2207 / ISSN 2707-2215 (en línea), mayo-junio, 2021, Volumen 5, Número 3. https://doi.org/10.37811/cl_rcm.v5i3.561 p.3761 
ANEXO N09: INSTRUMENTO: FICHA DE INVESTIGACIÓN

\begin{tabular}{|c|c|}
\hline E ANÁLISIS DOCUMENT & \\
\hline Nombre del Documento & $\begin{array}{l}\text { The Pandemic's Impacts on the Hardest-Hit Production } \\
\text { Sectors Will Affect One Third of Employment in the } \\
\text { Region and One Fourth of GDP }\end{array}$ \\
\hline Autor & CEPAL \\
\hline $\begin{array}{l}\text { Referencia Bibliográfica según norma } \\
\text { APA }\end{array}$ & $\begin{array}{l}\text { Cepal (2020). The Pandemic's Impacts on the Hardest- } \\
\text { Hit Production Sectors Will Affect One Third of } \\
\text { Employment in the Region and One Fourth of GDP. } \\
\text { Santiago de Chile, Chile. Recuperado de: } \\
\text { https://www.cepal.org/en/pressreleases/pandemics- } \\
\text { impacts-hardest-hit-production-sectors-will-affect- } \\
\text { one-third-employment }\end{array}$ \\
\hline Palabras claves de búsqueda & Acciones sociales, económicas, políticas y sanitarias. \\
\hline Palabras claves del texto & Disminución de activos financieros, COVID-19 \\
\hline $\begin{array}{l}\text { Ubicación (dirección } \\
\text { específica) }\end{array}$ & $\begin{array}{l}\text { https://www.cepal.org/en/pressreleases/pandemics- } \\
\text { impacts-hardest-hit-production-sectors-will-affect- } \\
\text { one-third-employment }\end{array}$ \\
\hline $\begin{array}{l}\text { Descripción del aporte del tema } \\
\text { seleccionado }\end{array}$ & $\begin{array}{l}\text { Nos informa acerca de la disminución de activos } \\
\text { financieros en los mercados de valores, así mismo en la } \\
\text { inversión extranjera directa (IED) y el PBI a nivel } \\
\text { regional se contraerá debido a la pandemia de COVID- } \\
19 \text { que nos encontramos enfrentando y así mismo es } \\
\text { como la CEPAL, plantea una serie de acciones sociales, } \\
\text { económicas, políticas y sanitarias. }\end{array}$ \\
\hline Enfoque & Cuantitativo, Cualitativo \\
\hline Alcance y diseño & $\begin{array}{l}\text { Alcance: Descriptivo - Exploratorio } \\
\text { Diseño: No Experimental. }\end{array}$ \\
\hline
\end{tabular}

Fuente: Elaboración propia.

\section{ANEXO N ${ }^{\circ}$ 10: INSTRUMENTO: FICHA DE INVESTIGACIÓN}

\begin{tabular}{|c|c|}
\hline & \\
\hline Nombre del Documento & $\begin{array}{l}\text { ¿Qué es el comercio intrarregional y por qué está } \\
\text { afectando a la globalización? }\end{array}$ \\
\hline A & Alami,Z. \\
\hline $\begin{array}{l}\text { Referencia Bibliográfica según norma } \\
\text { APA }\end{array}$ & $\begin{array}{l}\text { Alami, Z. (2019). ¿Qué es el comercio intrarregional y } \\
\text { por qué está afectando a la globalización?. Barcelona, } \\
\text { España. } \quad \text { Recuperado } \\
\text { https://internacionalmente.com/comercio- } \\
\text { intrarregional/ }\end{array}$ \\
\hline Palabras claves de búsqueda & Comerio Interregional \\
\hline Palabras claves del texto & Transacciones comerciales, blo \\
\hline $\begin{array}{lll}\begin{array}{l}\text { Ubicación } \\
\text { específica) }\end{array} & \text { (dirección } & \text { electrónica } \\
\end{array}$ & $\begin{array}{l}\text { https://internacionalmente.com/comercio- } \\
\text { intrarregional/ }\end{array}$ \\
\hline $\begin{array}{l}\text { Descripción del aporte del tema } \\
\text { seleccionado }\end{array}$ & $\begin{array}{l}\text { Definición del comercio interregional como el } \\
\text { desarrollo de transacciones comerciales, } \\
\text { fundamentalmente por países miembros de alianzas o } \\
\text { bloques económicos, aumentando la economía en } \\
\text { colectivo. }\end{array}$ \\
\hline Enfoc & Cuantitativo, Cualitativo \\
\hline Alcance y diseño & Alcance: Descriptivo - Exploratorio \\
\hline
\end{tabular}


Diseño: No Experimental.

Fuente: Elaboración propia.

\section{ANEXO N¹1: INSTRUMENTO: FICHA DE INVESTIGACIÓN}

\begin{tabular}{|c|c|}
\hline \multicolumn{2}{|c|}{ FICHA DE ANÁLISIS DOCUMENTAL } \\
\hline Nombre del Documento & $\begin{array}{l}\text { Una mirada al futuro post-COVID-19: hacia un nuevo pacto } \\
\text { social en América Latina y el Caribe }\end{array}$ \\
\hline Autor & Bonaglia, F., Parra, S. N., \& Zamora, J. J. V. \\
\hline $\begin{array}{l}\text { Referencia } \text { Bibliográfica } \\
\text { norma APA }\end{array}$ & $\begin{array}{l}\text { Bonaglia, F., Parra, S. N., \& Zamora, J. J. V. (2020). Una } \\
\text { mirada al futuro post-COVID-19: hacia un nuevo pacto } \\
\text { social en América Latina y el Caribe. Análisis Carolina, (21), } \\
\text { 1. Recuperado } \\
\text { https://scholar.googleusercontent.com/scholar?q=cache:Fm } \\
\text { uyAtv0q6sJ:scholar.google.com/+estrategias+de+integracio } \\
\text { n+economica+en+la+region+de+america+latina+y+el+cari } \\
\text { be\&hl=es\&as sdt=0,5\&as ylo=2020 }\end{array}$ \\
\hline Palabras claves de búsqueda & América Latina y el Caribe, COVID-19 \\
\hline Palabras claves del texto & Depreciación de moneda en América Latina y el Caribe. \\
\hline $\begin{array}{l}\text { Ubicación (dirección electrónica } \\
\text { específica) }\end{array}$ & $\begin{array}{l}\text { https://scholar.googleusercontent.com/scholar?q=cache:Fm } \\
\text { uyAtv0q6sJ:scholar.google.com/+estrategias+de+integracio } \\
\text { n+economica+en+la+region+de+america+latina+y+el+cari } \\
\text { be\&hl=es\&as_sdt=0,5\&as_ylo=2020 }\end{array}$ \\
\hline $\begin{array}{l}\text { Descripción del aporte del tema } \\
\text { seleccionado }\end{array}$ & $\begin{array}{l}\text { la agitación financiera, el deterioro de las condiciones } \\
\text { financieras y la fuga masiva de capital han causado la fuerte } \\
\text { depreciación de las monedas en América Latina y el Caribe }\end{array}$ \\
\hline Enfoque & Cuantitativo, Cualitativo \\
\hline Alcance y diseño & $\begin{array}{l}\text { Alcance: Descriptivo - Exploratorio } \\
\text { Diseño: No Experimental. }\end{array}$ \\
\hline
\end{tabular}

Fuente: Elaboración propia 
